\title{
GREAT GRAY OWL WEBB LAKE, MANITOBA
}

DAVID C. VANDERBURGH, 125 Dunfield Ave., Dauphin, Manitoba R7N OP1

Webb Lake is approximately 60 $\mathrm{km}$ northwest of Flin Flon in northwestern Manitoba. The area was heavily damaged during the forest fires of 1989. Only a few isolated patches of forest escaped the flames. There is a Bald Eagle nest in a large poplar in one of these sites at the northeast shore of the lake. In 1991, Archie Carruthers, Keith Elliott, and I observed eagles with young in this nest which is about 10 $\mathrm{m}$ above the ground.

During a six-day stay at Webb Lake, 5 to 11 June 1992, we frequently observed Bald Eagles in the vicinity of this nest, but were unable to determine if it was actually in use. While we were observing the eagle nest from our drifting boat on 8 June, Elliott noticed a second nest farther back in the bush. We landed and made our way through the bush and rocks until we could see a Great Gray Owl on the nest which was about $10 \mathrm{~m}$ above the ground in the fork of a large live poplar. This was approximately $50 \mathrm{~m}$ inland from the lake shore and about $30 \mathrm{~m}$ away from the Bald Eagle nest. The owl made no move to leave the nest during our 20-minute observation. It merely looked at us, peering down through the sticks on the nest edge when one of us approached the base of the tree briefly.

According to Bob Nero, although Great Gray Owls are expected to nest in this area, the nearest recorded nests have been $110 \mathrm{~km}$ south, near The Pas, and $135 \mathrm{~km}$ east, near Wabowden.

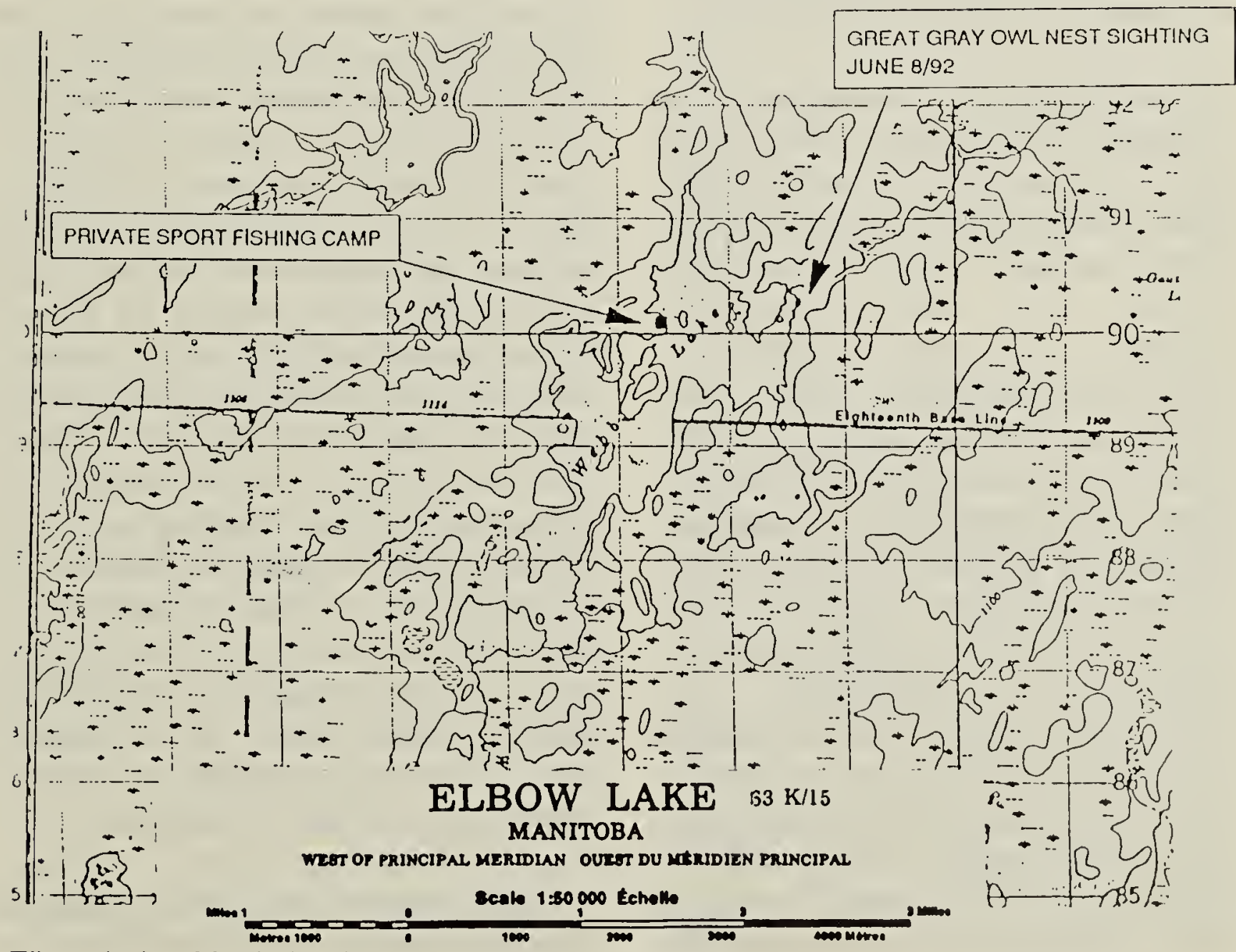

Elbow Lake, Manitoba. West of Principal Meridian. 